\title{
Variações individuais nos processos linguístico-cognitivos de envelhecimento normal ou patológico: Cada caso é um caso $^{1}$
}

\author{
Rosana do Carmo Novaes-Pinto \\ Universidade Estadual de Campinas (UNICAMP), Campinas, São Paulo, Brasil \\ ronovaes@iel.unicamp.br
}

DOI: http://dx.doi.org/10.21165/el.v46i2.1782

\begin{abstract}
Resumo
Este trabalho apresenta algumas reflexões desenvolvidas no âmbito do GELEP (Grupo de Estudos da Linguagem no Envelhecimento e nas Patologias/CNPq), orientadas pela Neurolinguística enunciativo-discursiva. Essa perspectiva teórico-metodológica concebe a linguagem como "atividade", como "trabalho" dos sujeitos com e sobre a língua para produzir enunciados - as "células vivas" dos processos dialógicos de significação (cf. BAKHTIN, 1997). Abordamos os limites das categorias clínicas diante da grande variação inter e intra-individuais observadas nos episódios dialógicos com indivíduos em processo de envelhecimento (normal ou patológico). As análises deixam entrever aspectos subjetivos que influenciam as diferentes formas de significação e de reorganização da linguagem - dentre os quais a relação do sujeito com sua doença (SACKS, 1997) -, que deve ser considerada tanto quanto a etiologia e/ou os sintomas, para a compreensão de um caso singular.
\end{abstract}

Palavras-chave: envelhecimento; afasia; envelhecimento patológico.

Individual variations in the linguistic-cognitive processes of normal or pathological aging: Each case is a different one

\begin{abstract}
This paper presents some reflections developed in the scope of GELEP (Group of Studies of Language in Aging and in Pathologies - Grupo de Estudos da Linguagem no Envelhecimento e nas Patologias/CNPq), grounded on enunciative-discursive Neurolinguistics. This theoreticalmethodological perspective conceives language as an "activity", a subjects" "work" with and on language aiming to produce "utterances" - the "live cells" of dialogical signification processes (cf. BAKHTIN, 1997). We approach the limits of clinical categories, considering the wide inter and intra-individual variations observed in dialogical episodes with subjects in normal or pathological aging processes. The analysis reveal subjective aspects that influence the different forms of signification and of language reorganization, among which is the subject's relation with his pathology (SACKS, 1997) that must be considered as much as the etiology and/or the symptoms to the comprehension of a single case.
\end{abstract}

Keywords: aging; aphasia; pathological aging.

\footnotetext{
${ }^{1}$ Este trabalho foi apresentado na mesa-redonda "Aquisição/desenvolvimento da linguagem e seus pontos de (des)encontros", no 64. Seminário do GEL, em Assis, S.P., em julho de 2016.
} 


\title{
Introdução
}

\author{
Há um outro cérebro que a ciência não estuda, ou só \\ considera marginalmente. $\dot{E}$, em primeiro lugar, o cérebro \\ de cada indivíduo, cada um diferente do outro; e, depois, \\ o cérebro de indivíduos pertencentes a culturas diferentes. [...] \\ Estuda-se um cérebro normal que, na realidade, não existe.
}

(MECCACI, 1984)

Este trabalho visa apresentar algumas das questões desenvolvidas nas pesquisas abrigadas pelo GELEP (Grupo de Estudos da Linguagem no Envelhecimento e nas patologias $/ \mathrm{CNPq}$ ), com ênfase nas variações individuais que caracterizam os processos linguístico-cognitivos no envelhecimento normal ${ }^{2}$ ou em condições patológicas ${ }^{3}$. As reflexões são orientadas pelos princípios teórico-metodológicos da Neurolinguística enunciativo-discursiva (COUDRY, 1988 [1986]), por sua vez filiada às abordagens sócio-histórico-culturais.

A primeira seção do artigo apresenta dois conceitos fundamentais da (neuro)linguística de orientação discursiva para sustentar a crítica aos modelos abstratos: o de indeterminação da linguagem e o de sujeito. São apresentadas, também, algumas noções postuladas por Vygotsky $(2001,2003)$ e por Luria (1977), com destaque para a de extracorticalidade, segundo a qual o cérebro e seu funcionamento são constituídos não apenas biologicamente, mas também por sua relação com o outro e com a cultura.

Em seguida, na segunda seção, serão discutidas questões relativas às categorias clínicas - entendidas nas teorias neuropsicológicas como um conjunto de sintomas (ou síndromes) - que servem tanto ao diagnóstico quanto ao acompanhamento terapêutico dos sujeitos. As categorias servem, também, para corroborar modelos psicolinguísticos ou neurolinguísticos, a partir da análise de unidades abstratas da língua e contextualizadas de seu uso.

A terceira parte será dedicada ao tema das variações individuais nos processos linguístico-cognitivos no envelhecimento - ainda muito pouco estudadas pela Linguística - que nos ajudam a pensar sobre a relação entre o normal e o patológico nessa fase da vida. Características que constituem o funcionamento normal passam a ser consideradas sintomas na fala dos idosos (NOVAES-PINTO, 2008). Os trabalhos desenvolvidos no âmbito do GELEP sobre esta temática, com destaque para os de Novaes-Pinto (2008), Novaes-Pinto e Oliveira (2015), Oliveira e Novaes-Pinto (2014) e Mazuchelli (2017), por sua vez fundamentados nos estudos de Beauvoir (1990), Neri (1991, 2001), Neri e Debert (1999), Peixoto (2008) e Gamburgo (2006), dentre outros vêm mostrando que muitos preconceitos derivam de estereótipos e mitos sobre o envelhecimento e também sobre a linguagem, estando diretamente relacionados à desvalorização do papel dos idosos na sociedade.

\footnotetext{
2 "Normal" será entendido, neste trabalho, como "sem patologia que impacte a linguagem e/ou outros processos cognitivos".

${ }^{3} \mathrm{O}$ texto destaca, sobretudo, a contribuição dos trabalhos realizados sobre essa temática por Oliveira e Novaes-Pinto (2014); Novaes-Pinto e Oliveira (2015) e Mazuchelli (2017).
} 
Depois de algumas décadas de acompanhamentos longitudinais de sujeitos afásicos, desde o trabalho pioneiro de Coudry (1986), compreendemos o que, a princípio, seria apenas um chavão - reiteradamente repetido para amenizar o peso dos diagnósticos e dos prognósticos - segundo o qual: "Cada caso é um caso". As análises dos trabalhos já realizados na área deixam entrever aspectos subjetivos que influenciam diretamente os modos de significação e de reorganização da linguagem, que devem ser considerados tanto quanto a etiologia ou os sintomas, na compreensão de um caso (SACKS, 1997; NOVAES-PINTO, 1999).

As perguntas feitas por Sacks e por Mecacci a esse respeito ainda merecem atenção e demandam uma tomada radical de posição dos teóricos da linguagem e dos terapeutas: A quem interessaria desenvolver uma ciência do sujeito, se a neurologia atual é mais voltada aos esquemas do que à realidade? (SACKS, 1997); se interessa à ciência um cérebro "médio" que, na verdade, não existe? (MECACCI, 1984).

Um dos desafios que nos são colocados no campo de estudos neurolinguísticos é avaliar, por um lado, o suposto valor das categorias para a compreensão dos processos de desenvolvimento linguístico-cognitivo (normal ou patológico, na infância ou no envelhecimento) e, por outro, em que medida elas são forjadas para corroborar modelos abstratos (NOVAES-PINTO, 1999).

Trata-se de uma "arena" em que muitos interesses (inclusive econômicos) estão em jogo, com o "enquadramento" dos sujeitos em categorias clínicas, em qualquer fase de suas vidas. Sobre essas questões, de caráter ético, nos orientamos, sobretudo, por princípios desenvolvidos pelo Círculo de Bakhtin (BAKHTIN, 1997) e por Lyon (1999), autor para quem as teorias, por melhores que sejam, de nada servem se não melhorarem de fato a vida das pessoas.

\section{Indeterminação da linguagem e subjetividade: conceitos fundamentais da Neurolinguística enunciativo-discursiva}

O sujeito não é alguém que é soberano em relação à língua, nem seu criador. Mas, também não é um repetidor ou reprodutor. Nem deus nem máquina. [...] O sujeito é sempre incompleto, imaturo, e ao mesmo tempo múltiplo: ao mesmo tempo social, histórico, psicológico e psicanalítico, biológico, linguístico. (COUDRY, 1988 [1986], p. 67)

O trabalho pioneiro de Coudry (1988 [1986]) - Diário de Narciso: afasia e discurso - deu origem à área de Neurolinguística enunciativo-discursiva (ou Neurolinguística Discursiva). Nessa obra, a autora explicita os princípios teóricometodológicos que guiaram sua pesquisa no campo das afasias, com importantes desdobramentos para a linguística e para a clínica fonoaudiológica com a linguagem. A autora enfatiza o papel central do sujeito na produção do discurso - aquele que produz enunciados, em situações efetivas de uso social da linguagem - e retoma dois conceitos fundamentais para a neurolinguística discursiva - indeterminação da língua(gem) e subjetividade - que são intimamente relacionados. Fundamenta-se, para isso, na reflexão de Franchi (1977), para quem "não há nada universal na linguagem, exceto o processo (sua força criadora e constitutiva)". Para o autor, a linguagem não é um dado ou um 
resultado; "mas um trabalho que dá forma ao conteúdo variável de nossas experiências, trabalho de construção, de retificação do vivido". Esse trabalho, coletivo, constitui o sistema simbólico mediante o qual se opera sobre a realidade, ao mesmo tempo em que "constitui a realidade como um sistema de referências em que aquele se torna significativo" (FRANCHI, 1992 [1977], p. 31).

A linguagem é concebida como atividade que integra o sujeito, o seu meio, a sua cultura e a sua história (COUDRY, 1988 [1986]). Tanto Franchi, quanto Coudry, ressaltam que as interações sociais são o lócus da produção dos significados. Nas palavras de Bakhtin (1997 [1929]), a interação é a solução dialética entre as posições dicotômicas que ou concebem a língua independente do sujeito (que Bakhtin chama de objetivismo abstrato) ou a concebem como uma criação individual (o subjetivismo idealista). Essas premissas são também a base para a crítica que a autora desenvolve sobre a prática neuropsicológica que privilegia as unidades abstratas da língua, descartando o contexto pragmático-discursivo na produção e compreensão dos enunciados.

Segundo Coudry (1988 [1986]), a metodologia quantitativo-estatística promoveu uma higienização na linguagem, eliminando todas as marcas de subjetividade, em nome de uma pretensa cientificidade, resultando em tabelas estatísticas, escalas diagnósticas e pesquisas com grupos-controle. A esse respeito, afirma que:

O sucesso ou insucesso do afásico em um ou mais desses testes serve como critério de classificação do tipo de afasia que o sujeito porta. [...] Apesar das correlações estatísticas que se podem estabelecer no estudo empírico entre tais sintomas e determinados tipos de lesão cortical, deve-se advertir para os cuidados que merecem tais procedimentos classificatórios. É claro que, para certos propósitos, os testes servem ao diagnóstico tipológico, mas talvez só ao diagnóstico. O fato de um sintoma ou um conjunto de sintomas permitirem uma classificação correta não assegura a via explicativa do fenômeno descrito. Observando os resultados dos sujeitos em tarefas específicas não se têm as indicações relevantes para a compreensão dos processos envolvidos e, consequentemente, não se têm pistas para a reelaboração de suas dificuldades. (COUDRY, 1988 [1986], p. 9).

Novaes-Pinto $(2011,2012)$ aponta que o trabalho de Coudry promoveu mudanças substanciais em relação aos estudos afasiológicos tradicionais e contribuiu decisivamente para uma melhor compreensão do funcionamento da linguagem e das variações individuais nas afasias, influenciando também as práticas clínicas em muitos centros de formação e de atuação fonoaudiológica no Brasil. Grande parte das reflexões teóricas e metodológicas no campo deriva de estudos longitudinais de casos. Essa metodologia permite avaliar os sujeitos ao longo do processo de (re)organização da linguagem, principalmente com relação às estratégias alternativas de significação que "permitem a eles voltar a participar do jogo da linguagem" (COUDRY, 1988 [1986]).

A seguir, passamos para o próximo item de nossa reflexão, considerando os dois conceitos apresentados até aqui - subjetividade e indeterminação da linguagem - que são apagados ou colocados em segundo plano pela neuropsicologia e neurolinguística tradicionais, com o objetivo de classificar os sujeitos nas categorias clínicas. 


\section{Categorias clínicas: o apagamento das diferenças individuais no estabelecimento de modelos teóricos}

Nossa concepção do sistema nervoso como uma espécie de máquina
ou computador é radicalmente inadequada e precisa ser
suplementada por conceitos mais dinâmicos, mais vivos

(SACKS, 1997).

Segundo Foucault (1998 [1963]), desde a Grécia antiga existe a necessidade de classificar os fenômenos patológicos. O conceito de "categoria clínica" está intimamente relacionado ao de "síndrome", ambos definidos a partir da constatação de um conjunto de sinais ou sintomas co-ocorrentes, em geral determinados estatisticamente. Segundo o autor, o objetivo da clínica é categorizar; descobrir qual é a doença que está acometendo o indivíduo e onde ela se localiza "sob sua pele". O autor faz uma crítica à descrição das doenças como sendo uma "coleção de sintomas", como uma forma de se alcançar uma "verdade". A semiologia seria o inventário desses sintomas, organizados ou recategorizados e reflete as condições da produção do conhecimento e das crenças de uma determinada sociedade, ou seja, depende da "vontade de verdade de uma época", fortemente marcada pela relação entre ver e dizer. Essa abordagem dos fenômenos orgânicos e psicológicos, segundo Foucault (1998), evidencia a preocupação classificatória e nominalista dos estudos desenvolvidos na prática da medicina nos séculos XVIII e XIX.

Novaes-Pinto (1999) dedicou-se ao estudo crítico das categorias clínicas e destacou o desprezo às variações individuais na sua compreensão. Quando os resultados estatísticos começaram a enfraquecer os modelos componenciais/modulares vigentes, muitos abandonaram o estudo de fenômenos afasiológicos alegando que: "as extremas variações encontradas entre os casos e, principalmente, no interior de um mesmo caso, tornavam a categoria clínica do agramatismo e por extensão todas as outras categorias clínicas sem importância teórica" (NOVAES-PINTO, 1999, p. 84). Segundo a autora, para compreender por que a variação na co-ocorrência de sintomas coloca grandes problemas aos modelos, é necessário rever alguns dos princípios que guiam tanto a definição de síndrome como a concepção de linguagem. Entre a inclusão de critérios subjetivos e os modelos abstratos, a neuropsicologia optou (e ainda continua optando) por salvar os modelos.

\section{Variações individuais nos processos linguístico-cognitivos no envelhecimento normal e patológico}

A doença é a perturbação de um equilíbrio, de uma harmonia. Não está em uma parte do homem, mas sim em todo o homem. [...] A doença não é somente desequilibrio ou desarmonia; ela é também - e, talvez, sobretudo - o esforço que a natureza exerce no homem para obter um novo equilibrio (CANGUILHEM, 1995 [1943], p. 19).

O tema do envelhecimento tem interessado, há muito tempo, a diversas áreas do conhecimento: filosofia, sociologia, antropologia, educação e, mais recentemente, 
também à linguística. Uma das discussões mais presentes nos estudos diz respeito à terminologia adequada ou "politicamente correta" para se referir a essa fase da vida (OLIVEIRA; NOVAES-PINTO, 2014; NOVAES-PINTO; OLIVEIRA, 2015). Ser velho é uma noção relacionada frequentemente à decadência e à incapacidade (PRETI, 1990). Nas sociedades capitalistas, significa pertencer à categoria de pessoas não-produtivas (PEIXOTO, 2008; NOVAES-PINTO, 2008).

Neste primeiro tópico da seção, serão abordadas questões relativas às categorias (terminologias) linguístico-cognitivas que dizem respeito ao envelhecimento, calcadas em dicotomias como terceira idade e melhor idade, idoso e velho, senilidade e senescência.

\subsection{O envelhecimento normal e suas categorias ${ }^{4}$}

It is very nice being an aged individual; however, it is very bad being and old one. (Victor Hugo)

Segundo Peixoto (2008), o termo "idoso" começou a ser mais comumente utilizado a partir do final da década de 60, influenciado pela legislação e pelos documentos que chegavam da França. Embora já fizesse parte do vocabulário português e pudesse ser utilizado como sinônimo de "velho", denotava maior respeito do que o segundo termo. O autor afirma que há evidências, em textos escritos, de que os termos não eram sinônimos de fato, pois estavam fortemente vinculados às diferentes classes sociais. Enquanto "velho" se referia a indivíduos pobres, "idoso" se referia a pessoas de classes mais altas (PEIXOTO, 2008; NOVAES-PINTO; OLIVEIRA, 2015).

Outro par de termos aparentemente neutros, mas também relacionado às diferentes esferas sociais, é "terceira idade" e "melhor idade". Enquanto o primeiro parece descrever naturalmente o período que vem após a idade adulta e que marca o final da vida produtiva, "melhor idade" ou "idade dourada" se refere a uma suposta qualidade de vida que poucos indivíduos podem usufruir após a aposentadoria - viajar, se exercitar e socializar, por exemplo. Novaes-Pinto (2008) aponta para as incongruências de se utilizar os termos "melhor idade" (ou "idade dourada") para se referir à maior parte da população que, em geral, não usufrui de um processo de envelhecimento com qualidade de vida, respeito e dignidade (OLIVEIRA; NOVAES-PINTO, 2014; NOVAES-PINTO; OLIVEIRA, 2015). Beauvoir (1990, p. 62, tradução nossa) faz uma crítica muito dura às sociedades sobre a forma como são tratados os indivíduos idosos e como as categorias linguísticas estão relacionadas aos fatores sociais. Em seu livro Old Age, ela se refere à categoria "last age" - última idade -, que revela o mais profundo abismo entre "um punhado de indivíduos privilegiados, capazes de viver a vida, e a grande maioria dos homens" 5 ". Ao envelhecerem, "os indivíduos são condenados - se não à miséria completa -, à pobreza, moradia desconfortável e solidão, o que lhes dá um senso de decadência e ansiedade generalizada" [...] Esse sofrimento impacta o corpo e pode causar doenças mentais, como um produto do sistema (BEAVOIR, 1990, p. 62). Nossa sociedade, assim, afirma a autora, é criminosa com relação ao tratamento dado aos idosos; o envelhecimento

\footnotetext{
${ }^{4}$ Para um tratamento mais aprofundado desta questão, ver Novaes-Pinto e Oliveira (2015) e Peixoto (2008), autor que analisa o par "velhice" ou "terceira idade" e termos pejorativos como "velhote".

${ }^{5}$ No original: "a handful of privileged individuals, able to live life and the vast majority of men".
} 
denuncia a falência de nossa inteira civilização.

Uma outra questão diz respeito ao fato de que a passagem da vida adulta para o período da velhice é regulada juridicamente. Segundo Minayo (2005), a Constituição Brasileira (1988), a Política Nacional para o Idoso (1994) e o Estatuto do Idoso (2003) consideram idosos os indivíduos acima de 60 anos de idade, enquanto em países desenvolvidos essa idade é de 65 anos. Segundo Minayo (2005), trata-se de uma decisão dos governos para regular pensões e aposentadorias. O envelhecimento, como todos os demais ciclos da vida, é uma construção político-social que tem a ver com o poder e a distribuição do poder.

Uma última dicotomia a que se pode recorrer, para caracterizar os processos de envelhecimento, que contrapõe o normal ao patológico é senescência e senilidade. Estes termos estão associados, respectivamente, com a ausência ou presença de condições patológicas. Enquanto o primeiro - senescência - se relaciona às mudanças fisiológicas e biológicas nos organismos que são comuns a todos os indivíduos - embora deva-se considerar a grande diversidade, influenciada também por fatores sócio-históricoculturais - senilidade é um termo comumente usado para se referir ao processo de envelhecimento em sujeitos comprometidos por doenças (LOURENÇO; MASSI, 2011; NOVAES-PINTO; OLIVEIRA, 2015): Não é raro, entretanto, ouvir este termo usado de forma pejorativa e até mesmo irônica, por exemplo, quando se quer dizer que alguém fala algo que não faz sentido: Fulano está senil. Isso deixa entrever, como afirma Mazuchelli (2017), que o discurso sobre os idosos está prenhe de estereótipos e mitos que revelam os preconceitos contra essa população. Nas palavras da autora (MAZUCHELLI, 2017, no prelo), "características que podem ser associadas a diferentes segmentos etários da população passam a ser marcas de envelhecimento e sintomas de uma patologia (de uma alteração, de um déficit, de um declínio)".

Segundo Novaes-Pinto (2008, p. 19), “quando o papel social do idoso se altera com a perda do status social em um determinado momento de sua vida, características de sua linguagem passam a ser também recusadas ou tidas até como sintomas de uma patologia" . O envelhecimento é, em diferentes graus, acompanhado por sinais físicos, fisiológicos e neuro/psicológicos. Doenças crônicas podem ser desenvolvidas ou acentuadas (hipertensão arterial, diabetes) e desencadear eventos agudos, como o infarto ou o AVC. Este, por sua vez, pode gerar afasias e outros problemas cognitivos. Não se pode negar, assim, a correlação entre o envelhecimento e eventos patológicos, embora esses eventos ou sintomas possam estar presentes também em sujeitos jovens e podem ser concebidos como parte de uma normalidade, especialmente quando se constata que, em muitas sociedades, a expectativa de vida está aumentando. Fala-se, hoje, da quarta idade (cerca de 80 anos) e da quinta idade (para os que ultrapassam os 100 anos). Podemos questionar se, nesses casos, alguns sinais ou sintomas (surdez, fraqueza nas pernas, perda da lucidez, dificuldade na articulação da linguagem e da adequação pragmáticodiscursiva, dentre outros) não seriam da ordem do normal, considerando-se uma média típica (não aritmética), segundo Canguilhem (1995). Qual seria o limite, afinal, para que um sinal seja considerado sintoma da doença ou relativa à normalidade?

\footnotetext{
${ }^{6}$ Isso chega a ser um paradoxo, como afirmam Novaes-Pinto e Oliveira (2015), uma vez que ser "idoso" ou "velho" é o destino natural de todos os seres humanos. Os autores refletem sobre as regras que regem a relação entre pais e filhos, nas mais diversas sociedades, desde a antiguidade, e que muitas vezes culmina em violência física e/ou psicológica da parte dos filhos.
} 
Uma categoria clínica recentemente criada é a de "declínio cognitivo leve", que consiste na presença de alguns sinais de senilidade (problemas de memória, certa desorientação espacial etc), sem comprovação em neuroimagem ou por meio de testes neuropsicológicos. Essa tem sido uma das categorias mais estudadas atualmente na neuropsicologia para se referir a uma fase de "passagem", que não é súbita, mas que faz parte da vida - assim como a puberdade, que consiste de mudanças físicas e psicológicas que ocorrem gradualmente e que está sujeita às variações individuais, que são dissolvidas quando se trata da regulação do curso da vida, do nascimento à morte (DEBERT, 2008). A autora afirma que os critérios de idade cronológica são impostos pelas sociedades para determinar deveres e direitos dos cidadãos. Fortes (1984) enfatiza que a idade cronológica seria irrelevante, a não ser pelo discurso jurídico.

Segundo Debert (2008), estudos etnográficos revelam que em todas as sociedades há a presença de algum tipo de classificação para as idades, embora a idade não explique, por si só, o comportamento humano. Lembra que os processos biológicos são construídos simbolicamente e têm rituais que definem as fronteiras entre estágios que não são necessariamente os mesmos em todas as sociedades. Não apenas o desenvolvimento biológico, mas também os ciclos individuais de vida e de maturidade devem ser levados em consideração para analisar a capacidade do sujeito para realizar tarefas. Concluindo, o envelhecimento pode ser uma experiência bastante distinta nas diferentes sociedades e entre os indivíduos de uma mesma sociedade. Isso é coerente com a neuropsicologia luriana, fundada sobre os postulados de Vygotsky, com relação ao conceito de "extracortical", e explica como a experiência individual, a relação do sujeito com a cultura e com o outro constitui o sujeito, assim como constituiu a espécie humana, do ponto de vista filogenético.

\subsection{Cada caso é um caso}

Damásio (1997), no artigo em que sintetiza o avanço obtido nas pesquisas na década do cérebro, ressalta que as descobertas não podem ainda explicar a maior parte das variações individuais entre sujeitos e as variações observadas na produção de um mesmo sujeito, nem sua relação com os fatores sociais, históricos e culturais que são constitutivos da linguagem e da cognição humana. Segundo Novaes-Pinto (1999), isso se deve a um descompasso entre postulados teóricos e escolhas metodológicas. Ao mesmo tempo em que se busca compreender o cérebro em funcionamento, os estudos neuropsicológicos se utilizam exclusivamente de instrumentos artificiais, como os testes metalinguísticos, ou mesmo das neuroimagens, cujos resultados também são interpretações estatísticas.

Sacks (1997), por outro lado, observava seus pacientes nas mais variadas situações de vida: no trabalho, nas interações familiares e sociais. Alguns de seus casos foram pesquisados durante anos, o que lhe permitiu uma sensibilidade para perceber as variações entre os casos dentre uma mesma síndrome. Seus estudos são relatados na forma de narrativas, um gênero essencial que resulta das pesquisas qualitativas. Sacks (1997) afirma que não se pode reduzir um fenômeno a fatores biológicos ou psico-sociais e morais. Há que se considerar, diz ele, "uma perspectiva interior, existencial, da própria pessoa afetada" (SACKS, 1997, p. 85), para uma visão mais totalizante da doença.

Outro aspecto relevante da pesquisa qualitativa é a opção por estudos de casos, que têm ajudado a construir e a solidificar as teorias linguísticas nas afasias. Miceli (2001, p. 658) enfatiza a contribuição dada por estudos de casos à pesquisa neuropsicológica, 
quando afirma que: "muito do progresso teórico na Neurologia e na Neuropsicologia das afasias resulta dos estudos detalhados de casos individuais de sujeitos afásicos". Segundo ele, os estudos de casos se constituem como "um instrumento heurístico poderoso na Neurologia/Neuropsicologia, e com o tempo eles têm provido um impressionante corpo de evidências, demonstrando a complexa arquitetura do sistema linguístico ${ }^{7}$ ". Kearns (1999) acredita que os estudos de casos sejam, hoje, amplamente aceitos na comunidade científica como instrumento legítimo para investigar questões clinicamente relevantes sobre a afasia. Com esses estudos, aprendemos a discutir nossos métodos e dados dentro de parâmetros científicos conhecidos. $\mathrm{O}$ autor enfatiza que não foi fácil fazer outros cientistas compreenderam, aceitarem e respeitarem nossos métodos e resultados, que diferem daqueles obtidos em condições experimentais, com grupos de sujeitos.

Antes de finalizar, trazemos alguns dados de episódios dialógicos, que deixam entrever alguns dos aspectos subjetivos da relação dos sujeitos com a afasia (marcados com negrito na transcrição)

O primeiro dado, dividido em 1 A e 1 B são do mesmo sujeito

\section{Dado 1: Variacões intra-individuais - sujeito P}

Dado 1 A) Contexto de produção: Coudry (1988, p. 136-137) estava mostrando a P algumas fotos de revistas. Havia uma em que um carro estava parado em um posto de gasolina, ao lado de uma bomba, sem o motorista. O frentista estava limpando o para-brisa com um tecido.

\begin{tabular}{|c|c|c|c|}
\hline Turno & Sujeito & Enunciado Verbais & $\begin{array}{r}\text { Enunciados não- } \\
\text { verbais/observações }\end{array}$ \\
\hline 01 & Imc & $\begin{array}{l}\text { O O que o homem está fazendo no } \\
\text { carro? }\end{array}$ & Mostrando a figura a $\mathrm{P}$. \\
\hline 02 & $\mathbf{P}$ & Gasolina. & \\
\hline 03 & Imc & Mas ele não está pondo gasolina. & $\mathrm{P}$ olha atentamente a figura. \\
\hline 04 & $\mathbf{P}$ & Vidros, certo? & \\
\hline 05 & Imc & $\begin{array}{l}\text { Tem só um vidro, certo? } \\
\text { O que ele está fazendo? }\end{array}$ & \\
\hline 06 & $\mathbf{P}$ & $\dot{E}[\ldots]$ vidros & \\
\hline 07 & Imc & E o que ele está fazendo? & \\
\hline 08 & $\mathbf{P}$ & Poeira, poeira & $\begin{array}{l}\text { P faz um gesto circular com a mão, } \\
\text { indicando a ação de limpar o vidro. }\end{array}$ \\
\hline 09 & Imc & $\begin{array}{l}\text { O que ele está fazendo? } \\
\text { Lim... }\end{array}$ & $\begin{array}{l}\text { Imc dá o prompting para } \\
\text { "limpando" }\end{array}$ \\
\hline 11 & $\mathbf{P}$ & {$[\ldots]$} & \\
\hline 12 & Imc & $\operatorname{Limp} \ldots$ & Estendendo o prompting \\
\hline 13 & $\mathbf{P}$ & Piando... limando... limpando... & \\
\hline
\end{tabular}

\footnotetext{
${ }^{7}$ Nas palavras de Miceli (2001, p. 658), eles representam "a powerful heuristic tool in cognitive Neurology/Neuropsychology, and with time they have provided an impressive body of evidence, demonstrating the complex architecture of the linguistic system" (Tradução nossa).
} 
Dado 1 B) Contexto de produção: Conversávamos com os sujeitos afásicos sobre o que tinham feito no final de semana.

\begin{tabular}{|l|l|l|l|}
\hline 1 & Iem & $\begin{array}{l}\text { E aí, o que o sr. fez no final de } \\
\text { semana? }\end{array}$ & Dirigindo-se a P \\
\hline 2 & $\mathbf{P}$ & $\begin{array}{l}\text { Olavo, Ordália e eu fomos a São } \\
\text { Paulo, fazer compras no shopping }\end{array}$ & \\
\hline
\end{tabular}

Os dados $1 \mathrm{~A}$ e $1 \mathrm{~B}$, acima, ilustram as diferentes produções de um mesmo sujeito. $\mathrm{P}$, com afasia não-fluente, seria considerado um agramático pelas características de sua fala, pelas dificuldades que apresenta com as palavras funcionais e por seu estilo telegráfico, especialmente presentes em 1 A. Entretanto, vemos que em $1 \mathrm{~B}$ ele apresenta um enunciado com todos os termos da oração presentes, o verbo flexionado no passado, as marcas de número (fomos) e plural (compras). Dados como este desafiam a semiologia afasiológica e os modelos componenciais que atribuem o agramatismo a comprometimentos sintáticos seletivos, como falhas na "competência" linguística. Em outras palavras, relacionando a produção diretamente ao que o sujeito teria perdido da gramática da língua. Nespolous (1997) é um autor que também critica esta teoria, de falha na competência, justamente pela observação de dados de um mesmo sujeito que ora produz as palavras funcionais e/ou morfemas flexionais, ora os substitui e ora os omite.

\section{Dado 2: Variacões inter-individuais}

Contexto da produção do dado: A Investigadora EM (Iem) conversa com os sujeitos afásicos sobre a atitude de se esforçar para se fazer entender, apesar de suas dificuldades.

\begin{tabular}{|c|c|c|c|}
\hline Turno & Sujeito & Enunciado Verbais & $\begin{array}{c}\text { Enunciados não- } \\
\text { verbais/observações }\end{array}$ \\
\hline 01 & CL & $\begin{array}{l}\text { Eu não sei falar, eu falo muito pouco... } \\
\text { Quando eu falo dá pra entender, mas faço } \\
\text { força pra eu falar, mexe aqui... um grande } \\
\text { esforçol/ Agora eu fujo de festa... fujo de } \\
\text { tudo... eu fui agora... né... no... aniversário } \\
\text { de dois netinhas... bisnetas // } \\
\text { Eu, faz... esse nome, eu num guardo. }\end{array}$ & $\begin{array}{l}\text { faz gesto sobre o peito indicando } \\
\text { que } \\
\text { A fono ajuda: "Gabriela e Laís"// }\end{array}$ \\
\hline 02 & Iem & $\begin{array}{l}\text { Fala um pouco mais sobre esta conduta da } \\
\text { senhora... procurar não ir às festas? A } \\
\text { senhora fez tudo pra não ir na festa delas? }\end{array}$ & \\
\hline $\mathbf{0 3}$ & $C L$ & $\begin{array}{l}\text { Eu fui... fui no aniversário e até escrevi pra } \\
\text { ela... } \\
\text { Não ir porque ninguém sabe que eu tenho } \\
\text { assim... e vão falar comigo e eu não posso } \\
\text { responder, então... }\end{array}$ & $\begin{array}{l}\text { aponta para a fono, que sabia sobre } \\
\text { a festa }\end{array}$ \\
\hline 04 & Iem & $\begin{array}{l}\text { Talvez a senhora não queira, mas a senhora } \\
\text { pode... }\end{array}$ & \\
\hline 05 & $C L$ & $\begin{array}{l}\text { Eu respondo mas fica mal pra mim assim. } \\
\text { Acho que não gosto... Agora casou a neta } \\
\text { da minha irmã, eu não fui. }\end{array}$ & \\
\hline 06 & Iem & $\begin{array}{l}\text { A senhora não quer se expor, falando dessa } \\
\text { maneira, não é isso? }\end{array}$ & \\
\hline
\end{tabular}




\begin{tabular}{|c|c|c|c|}
\hline Turno & Sujeito & Enunciado Verbais & $\begin{array}{l}\text { Enunciados } \\
\text { verbais/observações }\end{array}$ \\
\hline $\mathbf{0 7}$ & $C L$ & $\begin{array}{l}\text { Eu não quero expor porque vem conversar } \\
\text { comigo e eu não posso responder direito né, } \\
\text { então... prefiro não ir... [...] Mas eu fui } \\
\text { numa festa que houve agora. Então eu } \\
\text { procurei ficar perto de uma senhora velha } \\
\text { que sabia que eu tava doente... eu falei só } \\
\text { com ela. Com os outros não falei. Eu fui } \\
\text { cumprimentar as crianças, dei presente, mas } \\
\text { não falei... com ninguém. }\end{array}$ & \\
\hline 08 & Iem & Sr. SP também? & $\begin{array}{l}\text { Se direcionando a outro senhor } \\
\text { afásico }\end{array}$ \\
\hline 09 & SP & $\begin{array}{l}\text { O... o único lá... lá... baile... isso eu vô lá e... } \\
\text { minha mulher... o filho vai lá..., mas festa... } \\
\text { Eu não gosto... para que... agora... } \\
\text { agora... }\end{array}$ & \\
\hline 10 & Iem & $\begin{array}{l}\text { Quando o senhor tá com os amigos, a } \\
\text { família... }\end{array}$ & \\
\hline 11 & SP & $\begin{array}{l}\text { Aí tá certo. Mas.... Fala um pouco, mas... } \\
\text { depois... } \\
\text { "esquecí"! }\end{array}$ & $\begin{array}{l}\text { faz um gesto com a mão, próximo } \\
\text { à boca, indicando que as palavras } \\
\text { não saem. } \\
\text { Em discurso direto }\end{array}$ \\
\hline 12 & $\mathbf{C L}$ & $\begin{array}{l}\text { Quando a gente quer falar alguma coisa e } \\
\text { não fala, então... }\end{array}$ & \\
\hline 13 & $S P$ & $\begin{array}{l}\text { Num sei... então... vai lá.... fala "si, si, no, } \\
\text { no, si, si..." }\end{array}$ & $\begin{array}{l}\text { Usa o discurso direto indicando } \\
\text { que acaba apenas concordando } \\
\text { com os outros }\end{array}$ \\
\hline 14 & SI & $\begin{array}{l}\text { Eu falava, antes, sem parar, agora eu não } \\
\text { falo mais. }\end{array}$ & $\begin{array}{l}\text { Uma outra senhora afásica, } \\
\text { japonesa, entra no diálogo para } \\
\text { confirmar o que CL e SP estão } \\
\text { dizendo }\end{array}$ \\
\hline 15 & $\mathbf{C L}$ & $\begin{array}{l}\text { Ela fala e todo o mundo sabe o que ela tá } \\
\text { falando, mas... eu, pra falar outras coisas, } \\
\text { não posso falar }\end{array}$ & Indicando SI. \\
\hline 16 & SP & Ela vai... fala todo todo todo... & $\begin{array}{l}\text { Apontando para sua própria } \\
\text { cabeça... novamente referindo à } \\
\text { palavra que não vem. }\end{array}$ \\
\hline 17 & $\mathbf{C L}$ & $\begin{array}{l}\text { Eu falo, sim, mas muitas coisas eu não posso } \\
\text { falar }[. . .] \text { mas eu entendo... tudo que você } \\
\text { fala, eu entendo. }\end{array}$ & $\begin{array}{l}\text { Direcionando-se à interlocutora } \\
\text { Iem }\end{array}$ \\
\hline 18 & SP & Justamente... & Concordando com CL. \\
\hline 19 & $\mathbf{C L}$ & $\begin{array}{l}\text { Eu consigo falar, mas é muita dificuldade } \\
\text { pra mim [...]. Eu falava muitas coisas. }\end{array}$ & \\
\hline 20 & Iem & Falava melhor, com mais desenvoltura... & \\
\hline 21 & $\mathbf{C L}$ & $\begin{array}{l}\text { Mas é muito difícil eu falar assim, né, eu } \\
\text { falo e... entendo... porque eu tenho... eu } \\
\text { tinha voz boa... pra entender e agora } \\
\text { não... fico fazendo força e não falo } \\
\text { direito... }\end{array}$ & \\
\hline 22 & Iem & $\begin{array}{l}\text { Mas fala melhor do que falava antes, quando } \\
\text { teve o AVC! }\end{array}$ & \\
\hline 23 & $\mathbf{C L}$ & $\begin{array}{l}\text { Eu não sabia nada... mas agora eu sei... } \\
\text { muitas coisas... mas eu sei muito mais do } \\
\text { que eu sabia agora... quando eu fiquei } \\
\text { doente, eu não sabia nenhuma coisa... }\end{array}$ & \\
\hline
\end{tabular}


O episódio, dentre muitas questões acerca das afasias, deixa entrever uma das características responsáveis pela grande variação entre os casos: a relação do sujeito com a sua condição afásica. CL tem uma afasia fluente, enquanto a afasia de SP é não-fluente. Os dois sujeitos revelam como se comportam em situações sociais. CL compara sua linguagem atualmente com a que tinha antes do AVC (turnos 1, 15, 17, 19, 21 e 23). Tinha sido professora e certamente dominava diversos gêneros discursivos. Apesar de os outros dizerem que ela continua falando, ela avalia negativamente sua produção (turnos 5 e 7). Segundo CL, está melhor agora do que quando ficou afásica, mas antes era bem melhor. Essa avaliação justifica porque ele prefere retirar-se das interações sociais. Prefere não ir às festas, como afirma no turno 1: Agora eu fujo de festa... fujo de tudo. Ou fica perto de alguém que sabe que ela está doente: Mas eu fui numa festa que houve agora. Então eu procurei ficar perto de uma senhora velha que sabia que eu tava doente... eu falei só com ela. Com os outros não falei. Eu fui cumprimentar as crianças, dei presente, mas não falei... com ninguém (turno 7).

SP vai concordando com CF, sobre a dificuldade para se fazer compreender. Sua afasia é extremamente severa, mas mesmo assim ele se coloca como sujeito nos turnos interacionais, embora afirme que em algumas situações se limita a concordar ou discordar do que lhe dizem, sem entretanto poder argumentar defendendo um ponto de vista $(9,11$, 13 e 16).

É interessante notar que também SI, uma senhora japonesa que quase não falava nas sessões do CCA, também concorda com CL, ao afirmar, no turno 14: Eu falava, antes, sem parar, agora eu não falo mais.

\section{Questões de natureza ética: o ato responsável}

A opção teórico-metodológica que assumimos no estudo de processos de envelhecimento normal ou patológico nos levou a considerar, também, a complexidade do conceito de ato ético e responsável (BAKHTIN, 2010; SOBRAL, 2005; FARACO, 2009), não por sua aplicação direta a alguma instância de análise, mas porque sintetiza uma postura com relação ao agir na vida, que abrange também nossas atividades de docência e nas pesquisas e as escolhas teórico-metodológicas que devemos fazer ao longo do percurso. As reflexões são inspiradas por vários autores de vertentes sócio-históricoculturais, com destaque para as produções do Círculo de Bakhtin. Segundo Faraco (2009), os primeiros escritos do círculo pautaram as reflexões sobre linguagem, dialogia, alteridade e ética.

Segundo Bakhtin (2010), cada sujeito é responsável e deve responder por seus atos. A ética, afirma o autor, é um conjunto de obrigações e deveres concretos, sendo que o ato de pensar é o mais fundamental compromisso humano. A esse respeito, NovaesPinto (2011) diz que essa afirmação de Bakhtin "nos move; nos desloca de posições possivelmente mais cômodas" e conclui que "Acomodar-se em uma forma de pensar, repetindo o que se faz numa certa abordagem teórico-metodológica, ou porque é mais aceita numa comunidade científica, ou porque tem mais prestígio não pode ser considerado ético, nem tampouco responsável”. 


\section{REFERÊNCIAS}

BAKHTIN, M. Os gêneros do discurso. In: Estética da Criação Verbal. Tradução feita a partir da versão em francês por Maria Emsantina Galvão Pereira. São Paulo: Martins Fontes, 1997. p. 277-326.

. Para uma filosofia do ato responsável. São Paulo: Pedro \& João Editores, 2010.

BEAUVOIR, S. A velhice. Rio de Janeiro: Nova Fronteira, 1990.

BRASIL. Constituição da República Federativa do Brasil de 1988, 1988. Disponível em: $<$ http://www.planalto.gov.br/ccivil_03/constituicao/constituicaocompilado.htm>. Acesso em: 02 fev. 2014.

Lei $n^{\circ}$ 8.842, de 4 de Janeiro de 1994. Política Nacional do Idoso, 1994. Disponível em: <http://www.planalto.gov.br/ccivil_03/leis/18842.htm>. Acesso em: 17 fev. 2014.

Lei $n^{\circ} 10.741$, de 1 de Outubro de 2003. Estatuto do Idoso, 2003. Disponível em: <http://www.planalto.gov.br/ccivil_03/leis/2003/110.741.htm>. Acesso em: $17 \mathrm{fev}$. 2014.

CANGUILHEM, G. O Normal e o Patológico. Rio de Janeiro: Ed. Forense Universitária, 1995.

COUDRY, M. I. H. Diário de Narciso: discurso e afasia. São Paulo: Martins Fontes, 1988 [1986].

DAMÁSIO, A. What a difference a decade makes. Current Opinion in Neurology, Iowa, U. S. A: Rapid Science Publishers, v. 20, p. 177-178, 1997.

DAMICO, J. S. et al. Qualitative methods in aphasia research: basic issues. Aphasiology, London, v. 13, n. 9-11, p. 651-665, ago. 1999. Disponível em: $<$ http://dx.doi.org/10.1080/026870399401786>. Acesso em: 08 ago. 2011.

DEBERT, G. A antropologia e o estudo dos grupos e das categorias de idade. In: BARROS, M. M. L. Velhice ou terceira idade? Estudos antropológicos sobre identidade, memoria e politica. Rio de Janeiro: FGV, 2008.

FARACO, C. A. Linguagem e Diálogo - As Ideias Linguísticas do Circulo de Bakhtin. São Paulo: Parábola Editorial, 2009.

FOUCAULT, M. O nascimento da clínica. Rio de Janeiro: Forense Universitária, 1998 [1963].

. A Arqueologia do Saber. Rio de Janeiro: Forense Universitária, 1995 [1969].

FORTES, M. Age, generation, and social structure. In: KERTZER, D.; KEITH, J. (Ed.). Age and Antropological theory. Ithaca: Cornell University Press, 1984.

FRANCHI, C. Hipóteses para uma análise funcional da linguagem. 1977. 259 f. Tese (Doutorado em Linguística) - Instituto de Estudos da Linguagem, Universidade Estadual de Campinas, Campinas, 1975.

GAMBURGO, L. Envelhecimento e linguagem. Um estudo da linguagem como prática dialógica e social em idosos. 2006. 137 f. Dissertação (Mestrado em Educação) Faculdade de Educação, Universidade Metodista de Piracicaba, Piracicaba, 2006. 
GÓES, M. C. R. de. A abordagem microgenética na matriz histórico-cultural: uma perspectiva para o estudo da constituição da subjetividade. Cadernos Cedes, Relações de ensino: análises na perspectiva histórico-cultural, Campinas, n. 50, p. 9-25, 2000.

KEARNS, K. Qualitative research methods in aphasia: a welcome addition. Aphasiology, v. 13, n. 9-11, p. 649-650, 1999.

LOURENÇO, R. C.; MASSI, G. Linguagem e Velhice: Considerações acerca do papel da escrita no processo de envelhecimento. Curitiba: Juruá Ed., 2011.

LURIA, A. Neuropsychological studies in aphasia. Amsterdam: Sweets \& Zeitlinger B. V., 1977.

LYON, J. A commentary on qualitative research in afasia. Aphasiology, v. 13, n. 9-11, p. 681-687, 1999.

MAZUCHELLI, L. P. A Dificuldade para Encontrar Palavras: inferências a partir da análise qualitativa de entrevistas com sujeitos idosos. Revista Estudos Linguísticos, São Paulo, v. 46, 2017 (no prelo).

MECACCI, L. Conhecendo o cérebro. São Paulo: Nobel Instituto Italiano di Cultura di São Paulo, 1984.

MINAYO, M. C. Violência contra idosos: O avesso do respeito à experiência e à sabedoria. Brasília: Secretaria Especial dos Direitos Humanos, 2005.

NERI, A. L. Envelhecer num país de jovens. Significados de velho e velhice segundo brasileiros não idosos. Campinas: Editora da UNICAMP, 1991.

. Maturidade e Velhice. Trajetórias individuais e socioculturais. Campinas: Papirus Ed. 2001.

NERI, A. L.; DEBERT, Velhice e Sociedade. Campinas: Papirus Ed., 1999.

NESPOLOUS, J. L. A contribuição das ciências cognitivas - e, particularmente, da Psicolinguística cognitiva - ao estudo das alterações de linguagem ou "do descritivo ao interpretativo". In: RODRIGUES, N.; MANSUR, L. Temas em Neuropsicologia, Série de Neuropsicologia, v. 1, p. 19- 37, 1997.

OLIVEIRA, M. V. B.; NOVAES-PINTO, R. C. On the relation between memory and language from a historical-cultural perspective in neurolinguistics. Southern Semiotic Review, v. 4, p. 1-15, 2014.

NOVAES-PINTO, R. C. A contribuição do estudo discursivo para uma análise crítica das categorias clínicas. 1999. 272 f. Tese (Doutorado em Linguística) - Instituto de Estudos da Linguagem, Universidade Estadual de Campinas. Campinas, 1999.

Preconceito linguístico e exclusão social nas chamadas patologias de linguagem. Avesso do Avesso: Revista de Educação. FAC-Araçatuba, São Paulo, v. 5, n. 5, p. 8-36, 2008.

Desafios metodológicos da pesquisa em Neurolinguística no início do século XXI. Revista Estudos Linguísticos, v. 40, p. 966-980, 2011. 
A social cultural-approach to aphasia: contributions from the work developed at a center for aphasic subjects. In: TAN, Ü. (Ed.). Latest Findings in Intellectual and Developmental Disabilities Research, Croatia, 2012b, p. 219-244. Disponível em: $<$ http://www.intechopen.com/articles/show/title/a-social-cultural-approach-to-aphasiacontributions-from-the-work-developed-at-a-center-for-aphasic $>$. Acesso em: 01 mar. 2012.

NOVAES-PINTO, R. C.; OLIVEIRA, M. V. B. Uncovering hidden meanings in legal discourse on the elderly: a semioethical perspective. Semiotica (online), p. 1-21, 2016.

NOVAES-PINTO, R. C.; SANTANA, A. P. A semiologia das afasias. In: MANCOPES, R.; SANTANA, A. P. (Org.). Perspectivas na clínica das afasias: o sujeito e o discurso. São Paulo: Editora Santos, 2009a. p. 18-40.

NOVAES-PINTO, R. C.; SANTANA, A. P. Semiologia das afasias: uma discussão crítica. Psicologia: Reflexão e Crítica, Porto Alegre, n. 22, v. 3, p. 413-421, 2009 b.

OLIVEIRA, M. V. B.; NOVAES-PINTO, R. C. On the relation between memory and language from a historical-cultural perspective in neurolinguistics. Southern Semiotic Review, v. 4, p. 1-15, 2014.

PEIXOTO, C. Entre o estigma e a compaixão e os termos classificatórios: velho, velhote, idoso, terceira idade. In: MORAES, M.; BARROS, L. (Org.). Velhice ou terceira idade? Estudos antropológicos sobre identidade, memoria e politica. Rio de Janeiro: FGV, 2008.

PRETI, D. A linguagem dos idosos. São Paulo: Contexto, 1991.

SACKS, O. O homem que confundiu sua mulher com um chapéu. São Paulo: Companhia das Letras, 1997.

SOBRAL, A. Ético e estético: na vida, na arte e na pesquisa em Ciências Humanas. In: BRAIT, B. (Org.) Bakhtin: conceitos-chave. São Paulo: Editora Contexto, 2005.

VYGOTSKY, L. S. A formação social da mente: o desenvolvimento dos processos psicológicos superiores. Tradução de José Cipolla Neto; Luís Silveira Menna Barreto; Solange Castro Afeche. 6. ed. 6 tiragem. São Paulo: Martins Fontes, 2003.

A construção do pensamento e da Linguagem. Tradução de Paulo Bezerra. São Paulo: Martins Fontes, 2001.

Recebido em: 30/08/2016

Aprovado em: 29/11/2016 